\title{
Correction to: Age and sex differences in numerical responses, dietary shifts, and total responses of a generalist predator to population dynamics of main prey
}

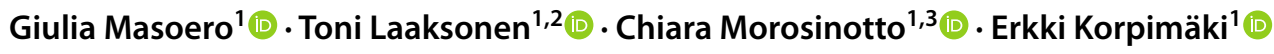

Published online: 2 January 2021

๑) Springer-Verlag GmbH Germany, part of Springer Nature 2020

\section{Correction to: Oecologia (2020) 192:699-711 \\ https://doi.org/10.1007/s00442-020-04607-x}

The authors would like to correct errors in the original publication of the article. In Table 3, one column was missing, the one containing the data on the estimated number of consumed bank voles. The corrected version of Table 3 can be found here.

The original article can be found online at https://doi.org/10.1007/ s00442-020-04607-x.

Giulia Masoero

giulia.masoero@gmail.com

1 Section of Ecology, Department of Biology, University of Turku, 20014 Turku, Finland

2 Natural Resources Institute Finland (Luke), Turku, Finland

3 Novia University of Applied Sciences, Bioeconomy Research Team, Raseborgsvägen 9, 10600 Ekenäs, Finland 


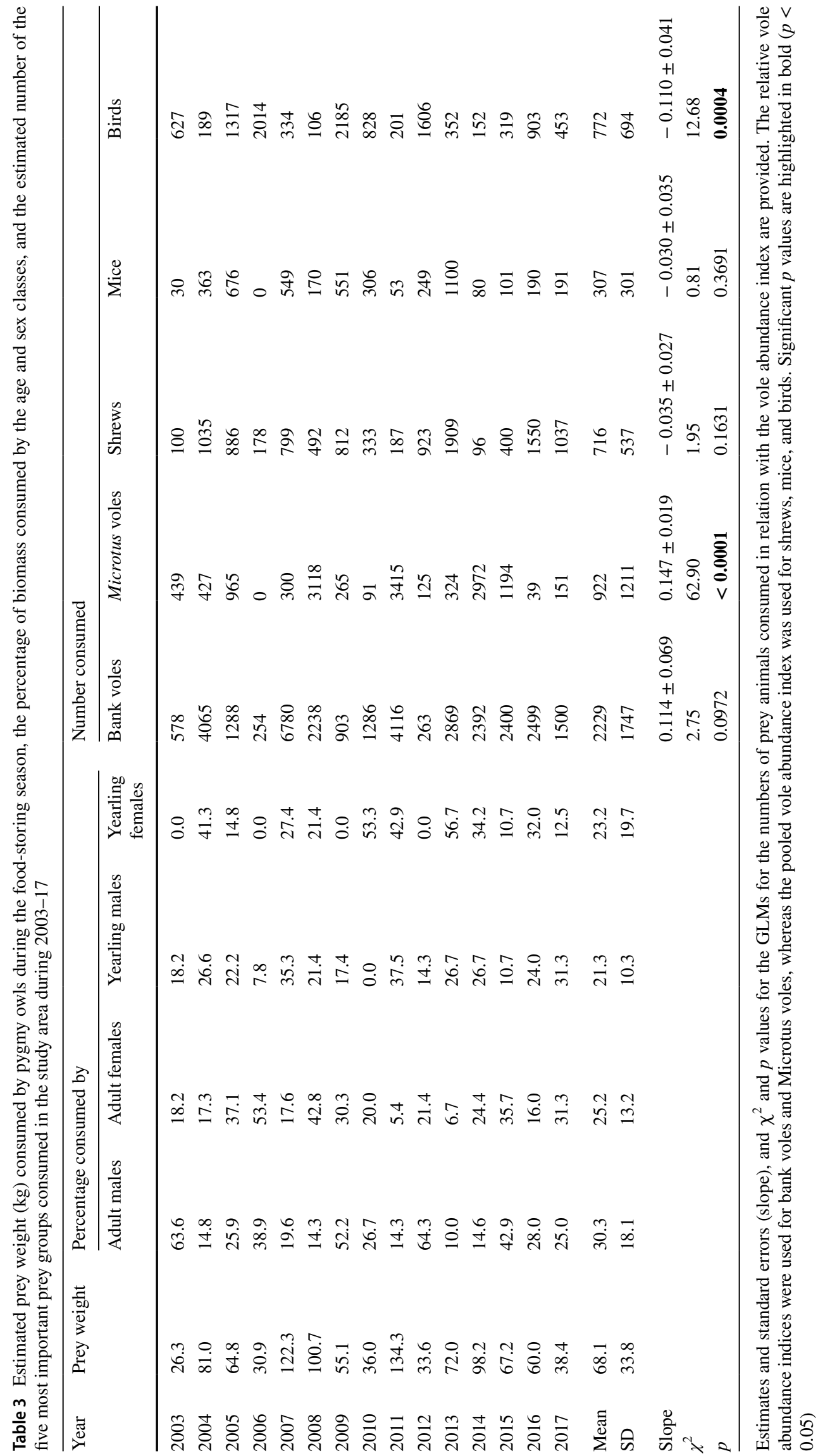

